\title{
A proposal of Brazilian Society of Surgical Oncology (BSSO/SBCO) for standardizing cytoreductive surgery (CRS) plus hyperthermic intraperitoneal chemotherapy (HIPEC) procedures in Brazil: pseudomixoma peritonei, appendiceal tumors and malignant peritoneal mesothelioma
}

\section{Proposta de padronização da Sociedade Brasileira de Cirurgia Oncológica (BSSO/SBCO) para procedimentos de citorredução cirúrgica (CRS) e quimioterapia intraperitoneal hipertérmica (HIPEC) no Brasil: pseudomixoma peritoneal, tumores do apêndice cecal e mesotelioma peritoneal maligno}

Thales Paulo Batista, TCBC-Pe1,2; Bruno José Queiroz Sarmento3; Janina Ferreira loureiro4; Andrea Petruzziello 5,11; Ademar Lopes, ECBC-SP6; Cassio Cortez Santos7\%; Cláudio de Almeida Quadros, TCBC-BA ${ }^{8}$; Eduardo Hiroshi Akalshi, TCBC-SP9; Eduardo Zanella Cordeiro ${ }^{10}$; Fellipe José Fernandez Coimbra, TCBC-SP11; Gustavo Andreazza laporte 12; Leonaldson Santos Castro, TCBC-RJ4,13; Ranyell Matheus Spencer Sobreira Batista6; Samuel Aguiar Júnior, TCBC-SP6; Wilson Luiz Costa Júnior ${ }^{11}$; Fábio Oliveira FerrelRA, TCBC-SP6; on behalf of the BSSO/ SBCO Committee on Peritoneal Surface Malignancies and HIPEC.

\section{A B S T R A C T}

\begin{abstract}
Cytoreductive surgery plus hyperthermic intraperitoneal chemotherapy has emerged as a major comprehensive treatment of peritoneal malignancies and is currently the standard of care for appendiceal epithelial neoplasms and pseudomyxoma peritonei syndrome as well as malignant peritoneal mesothelioma. Unfortunately, there are some worldwide variations of the cytoreductive surgery and hyperthermic intraperitoneal chemotherapy techniques since no single technique has so far demonstrated its superiority over the others. Therefore, standardization of practices might enhance better comparisons between outcomes. In these settings, the Brazilian Society of Surgical Oncology considered it important to present a proposal for standardizing cytoreductive surgery plus hyperthermic intraperitoneal chemotherapy procedures in Brazil, with a special focus on producing homogeneous data for the developing Brazilian register for peritoneal surface malignancies.
\end{abstract}

Keywords: Injections. Intraperitoneal. Hyperthermia, Induced. Drug Therapy. Peritoneal Neoplasms.

\section{INTRODUCTION}

C ytoreductive surgery (CRS) plus hyperthermic intraperitoneal chemotherapy (HIPEC) has emerged as a major comprehensive treatment of peritoneal surface malignancies, especially for malignancies that remain confined to the abdominopelvic cavity with litt- le invasion of the underlying organs and no metastatic spread $^{1}$. This multimodal approach has proved to be an effective curative treatment or a salvage therapy for a number of patients suffering from peritoneal surface malignancies ${ }^{2,3}$ and is currently the standard of care for appendiceal epithelial neoplasms and Pseudomyxoma peritonei (PMP) syndrome ${ }^{4,5}$ as well as diffuse malignant

1 - Medicina Integral Professor Fernando Figueira Institute, Department of Surgery / Oncology, Recife, PE, Brazil. 2 - University of Pernambuco, Department of Surgery, Recife, PE, Brazil. 3 - Hospital de Base of the Federal District, Service of Surgical Oncology, Brasília, DF, Brazil. 4 - Complexo Hospitalar de Niterói, Service of Surgical Oncology, Niterói, RJ, Brazil. 5 - Marcelino Champagnat Hospital, Department of Surgical Oncology, Curitiba, PR, Brazil. 6 - AC Camargo Cancer Center, Department of Pelvic Surgery, São Paulo, SP, Brazil. 7 - Hospital Geral de Fortaleza, Department of Surgery, Fortaleza, CE, Brazil. 8 - São Rafael Hospital, Service of Surgical Oncology, Salvador, BA, Brazil. 9 - Hospital das Clínicas, University of São Paulo, Department of Surgical Oncology, São Paulo, SP, Brazil. 10 - Hospital de Caridade, Department of Surgery, Florianópolis, SC, Brazil. 11 - AC Camargo Cancer Center, Department of Abdominal Surgery, São Paulo, SP, Brazil. 12 - Santa Casa de Misericórdia de Porto Alegre, Department of Surgical Oncology, Porto Alegre, RS, Brazil. 13 - Nacional Cancer Institute, Service of Abdomino-Pelvic Surgery, Rio de Janeiro, RJ, Brazil. 
peritoneal mesothelioma (DMPM) ${ }^{6,7}$. The rationale of combining heat with intraperitoneal chemotherapy is the added benefit of the synergistic effect of heat and cytotoxic drugs ${ }^{8}$. This approach allows full peritoneal chemotherapy perfusion and exposure of poorly vascularized tumoral tissue in the abdomen with high concentrations of cytotoxic agents before the formation of adhesions that might limit peritoneal fluid circulation. The blood-peritoneal barrier limits the passage of these high doses into the plasma and reduces the risk of systemic toxicity. Heat itself has a direct cytotoxic effect; it also enhances the effect of certain antimitotic agents (i.e.: mitomycin C, cisplatin, oxaliplatin) as well as increases their penetration into tumor tissue ${ }^{8,9}$. Some studies also reveal that hyperthermia can reduce the mechanisms of cellular resistance to cisplatin ${ }^{10}$ and induce an efficient anticancer immune response via exposure of cell surface heat shock proteins ${ }^{11,12}$. Furthermore, this technique is delivered intraoperatively, avoiding the need for implantation of peritoneal access devices, hence reducing catheter-related morbidity ${ }^{13,14}$.

In Brazil, the management strategies by peritoneal surface malignancies with CRS/HIPEC have increased by efforts of the Brazilian Society of Surgical Oncology (BSSO) and its members. Following some pioneering initiatives, CRS/HIPEC continued to gain interest throughout the country and several reports of initial or consolidated experiences have shown the efficacy of this treatment in Brazil15-29.

In summary, these data are heterogeneous in terms of technical particularities and antimitotic agents, but this combined therapeutic approach has been performed with acceptable morbimorbidity and mortality and appears to provide a survival benefit over conventional treatments in many of our centers. In these settings, the BSSO points out that no single technique has so far demonstrated its superiority, and several variations in techniques have produced heterogeneous and no comparable results, which require some standardization of practices that might permit systematic comparisons ${ }^{30}$. Thus, we considered it important to present a statement produced by BSSO in order to guide the current clinical practice concerning CRS/HIPEC procedures in Brazil, with a special focus on producing homogeneous data for the developing Brazilian register for peritoneal surface malignancies.

\section{METHODS}

\section{Development Process}

This proposal for standardizing HIPEC procedures addresses the following clinical points: 1) common technical aspects; 2) patients selection; 3) intraperitoneal chemotherapy schedules; and 4) perioperative oncological management. The BSSO Committee on Peritoneal Surface Malignancies and HIPEC were asked to consider the available evidence, contribute to the development of recommendations, provide a critical review, and finalize this proposal. Initially, few members (i.e.: the first four listed authors) of this committee were responsible for performing a non-systematic review of the most relevant scientific literature and writing a core proposal of standardization. Thereafter, all members reviewed the former version for discussion and improvements, and approved an ultimate version. An external review was also required from three invited experts in CRS/HIPEC procedures from outside Brazil (i.e.: Sugarbaker PH, Verwall VJ and Deraco M), just before submission for editorial review and consideration for publication.

Due to the lack of high-level evidence for all specific points to be addressed, recommendations were made based on large clinical experience and expert options. For technical aspects, proposals of standardization also considered results from a recent survey undertaken by the BSSO concerning the development of CRS/HIPEC procedures throughout our country. Accordingly, the use of words like "must" (or "must not") and "should" (or "should not") indicates that a course of action is proposed based on proportional levels of agreement amongst large clinical experiences and expert options, whereas the words "recommend" and "suggest" were also applied in a similar manner.

\section{Disclaimers}

The information herein provided by the BSSO should not be relied upon as being complete or accurate, nor should it be considered as inclusive of all proper treatments or methods of care or as a statement of the standard of care. The information addresses only the 
topics specifically identified therein and is not applicable to other interventions, diseases, or stages of diseases, and is not intended to substitute for the independent professional judgment of the treatment provider, as the information does not account for individual variation among patients. Thus, the use of this information is voluntary and BSSO assumes no responsibility for any injury or damage to persons or property arising out of or related to any use of this information, or for any errors or omissions.

\section{Conflicts of Interest}

All members of the committee were asked to list any conflicts of interest and to complete the journal's disclosure form, which requires disclosure of financial and other interests, including relationships with commercial entities that are reasonably likely to experience direct regulatory or commercial impact as a result of promulgation of this proposal for standardization. In accordance with this policy, all members of this BSSO committee did not disclose any relationships constituting a conflict under the policy.

\section{PROPOSAL FOR STANDARDIZING}

\section{PROCEDURES}

\section{Patients Selection}

Careful patient selection is the cornerstone for the management of peritoneal surface malignancies and must involve a comprehensive evaluation considering clinical, radiological, laboratory and histological findings. The suggested minimal preoperative investigations include: 1) physical examination; 2) cardiopulmonary investigation with cardiac echography and functional pulmonary exploration; 3) renal function investigation by creatininemia and clearance of creatinine; 4) biological evaluation of the hepatic function; 5) evaluation of nutritional state by body mass index and albuminemia; and 6) extent of disease and staging by contrast-enhanced multisliced computed tomography and, if necessary, FDG-PET, magnetic resonance imaging or laparoscopic exploration ${ }^{31,32}$. Tumor markers are also helpful and should be considered on the workup ${ }^{33}$. There is also an overall consensus that patients fit for a major comprehensive oncological approach such as CRS/HIPEC are those ASA I-II, performance status of $0-2$, with no limiting comorbidities and aged lower than 65-70 years ${ }^{31,34,35}$.

Preferentially, an experienced pathological team should review the preoperative clinical and histological findings for a proper diagnostic confirmation. Reports of pathological findings for PMP should be in line with the Consensus for Classification and Pathologic Reporting of Pseudomyxoma Peritonei and Associated Appendiceal Neoplasia by the Peritoneal Surface Oncology Group International (PSOGI) ${ }^{36}$ and standards of the 7 th edition of the AJCC staging classification, as appropriated ${ }^{37}$.

Due to its rarity, review by an expert pathologist using a panel of at least two positive and two negative immunohistochemical stains is required to make a definitive diagnosis of DMPM. The specific panel depends on the differential diagnosis, but common positive markers include calretinin, D240 , CK 5/6, and WT-1, and some frequently used negative markers include MOC-31, PAX8, BG8, Ber-EP4, B72.3, CEA, and CDX-238,39. Accordingly, these peritoneal tumors should be staged by the tumor-node-metastasis (TNM) system proposed by the PSOGI based on analysis of a multi-institutional database ${ }^{40}$, whereas two distinct pathologic subtypes of borderline malignant potential named well-differentiated papillary mesothelioma (WDPM) and benign multicystic mesothelioma (BMM) that are much more common in the peritoneum than in the pleura should also be well recognized before treatment planning because of their better outcomes $^{38}$.

Patients with DMPM of histological biphasic or sarcomatoid subtype must not be considered for treatment with CRS/HIPEC6 as well as those tumors with high expression of Ki67 (i.e.: $=25 \%$ by immunohistochemical evaluation $)^{41}$ that are usually 
diagnosed under a high tumor load. Similarly, patients with both $\mathrm{Ki}-67>10 \%$ and $\mathrm{PCI}>17-20$ are also unlikely to benefit from the procedure and should be considered for other treatment proto-

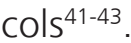

The extent of peritoneal spreading represents one of the most important prognostic factors and the tumor burden as estimated by PCI (peritoneal cancer index) provides a good probability of achieving a complete cytoreduction during CRS for peritoneal malignancies. However, more than the tumor burden, the distribution of peritoneal spreading in the abdomen constitutes the principal limitation for performing $\mathrm{CRS}^{31}$. In these settings, the most frequent contraindications for CRS/HIPEC are extra-abdominal metastasis, massive involvement of the small bowel and its mesentery, hepatic pedicle and gastro-hepatic ligament, gross retroperitoneal lymph node involvement, and ureteral or biliary obstruction, whereas a restrictive cut-off value for $\mathrm{PCI}$ (i.e.: $\mathrm{PCl}>20$ ) also should not be applied as an absolute exclusion criterion for CRS/HIPEC suffering of $\mathrm{PMP}^{31,44,45}$.

\section{Common Technical Aspects}

Techniques of advanced CRS were previously standardized and described by Sugarbaker and must be followed accordingly with minimal variations of procedures ${ }^{46-48}$. On the other hand, several techniques of HIPEC have been described since its first use in the 80 's ${ }^{49}$. Variable particularities of HIPEC include installation circuit, timing of visceral anastomoses (i.e.: before or after HIPEC), length of perfusion, target temperatures, type and volume of perfusate, and others. Herein, a started point of discussion is performing HIPEC as a closed or open abdominal (coliseum) technique. Whilst there are no convincing data favoring any technique ${ }^{50-52}$, we have chosen for the use of a closed technique based on the simplicity of this method and decreased contamination risk ${ }^{53}$, as well as because most of the centers perform closed HIPEC procedures in Brazil. In these settings, we also propose a minimum of $4 \mathrm{~L}$ (ranging from 4-6L) of perfusate into the abdominal cavity in order to counterbalance the theoretical drawbacks of closed techniques in comparison to the open approach since a maximal distention of the abdomen enhances the thermal homogeneity throughout the peritoneal cavity ${ }^{54}$ and facilitates drug distribution into the whole abdomen, ensuring that every site of the diffuse peritoneal disease receives the optimal treatment. At this point, we also suggest an inflow temperature of $44^{\circ} \mathrm{C}$ in order to maintain a critical threshold for potentiating cytotoxic chemotherapy of above $40^{\circ} \mathrm{C}$ into the peritoneal cavity ${ }^{55}$, with an optimal range of $41-43^{\circ} \mathrm{C}$ as average between in- and out-drains. In regards of flow rate parameters, our purpose is that 300$500 \mathrm{~mL} / \mathrm{min}$ should be applied during the "patientfilling phase" and thus increased to $700 \mathrm{~mL} / \mathrm{min}$ during the "circulation" and "HIPEC" phases" ${ }^{56-58 .}$ Similarly, as carrier solutions, we suggest the use of $1.5 \%$ dextrose isotonic peritoneal dialysis solutions for any drug protocol proposed ${ }^{53}$ here, even for those oxaliplatin-based schedules ${ }^{59,60}$. Because the main risk of HIPEC is related to direct or indirect skin exposure to antiblastic drugs, the use of two pairs of gloves should be mandatory to protect the surgical team during abdomen manipulation after the "emptying phase"61-63.

In the light of reducing morbidity related to CRS, we point out that right hemicolectomy is not routinely required in PMP resulting from mucinous appendiceal neoplasms at low risk of relapse or lymph node involvement ${ }^{64,65}$, and that a more conservative approach confining the peritonectomy to where there is evidence of more solid disease is also a suitable approach for PMP/ Appendiceal Tumors ${ }^{66}$. On the contrary, we suggest a complete parietal peritonectomy in patients with DMPM based on a controlled study conducted by Baratti et al. ${ }^{67}$ demonstrating improved sur- 
vival outcomes after the radical approach. Another main controversial issue concerning the technical aspects of CRS is the timing of bowel anastomoses. Recently, the BSSO developed an online survey involving the technical aspects of CRS/HIPEC and achieved no consensus in regards to this issue applying a simplified two-round-based Delphi method, in spite of the fact that previous reports from the 5th International Consensus Metting on Peritoneal Surface Malignancies Treatment had favored the "after HIPEC" approach (54\%) for the closed abdomen technique ${ }^{66}$. Due to the lack of evidence to support a strong recommendation, we propose that intestinal anastomoses should be performed before HIPEC based on no reports of recurrence involving the anastomotic area as an isolated or first site of relapse and because of the lower time of chemotherapeutic exposure for the surgical team. Further, in cases requiring an esophago-jejunal anastomosis after total gastrectomy, this approach may also reduce the exposure of mediastinum to cardiotoxic drugs as cisplatin. In a similar manner, a diverting ileostomy is not routinely recommended and may be avoided at the surgeon's discretion after colorectal stapled anastomoses ${ }^{68}$, especially because restoration of bowel continuity is often related to high rate of temporary stomas that will not be subsequently reversed ${ }^{69}$ as well as to postoperative complication ${ }^{70}$.

Perioperative care practices for $\mathrm{CRS} / \mathrm{HI}$ PEC are widely variable nationally and internationally and standardization of such practices offers an opportunity to incorporate experience from high-volume centers and may enhance patient outcomes $^{30}$. In these settings, one of the most recent reviews involving several aspects related to peri, intra and postoperative management of patients undergoing CRS/HIPEC have just been published by Raspé et al. ${ }^{53}$ and summarizes the main understanding of this committee to improve periopertive care standards for the procedures. Following these review of evidences, we highlight that a goal-directed fluid therapy using noninvasive monitoring tool of hemodynamic parameters improves outcome in terms of major abdominal and systemic postoperative complication incidences or length of hospital stay compared with the standard approach ${ }^{71,72}$. We also maintain that implementation of fast-track protocols are feasible in order to accelerate recovery, reduce morbidity and shorten convalescence to ultimately improve outcomes and reduce costs, especially for those patients with low $\mathrm{PCl}$ not requiring digestive anastomosis $53,73-75$. Our proposal is also along the line that ICU stay directly following CRS/HIPEC should be preferably based on the extent or resections performed and individual patient characteristics and risk factors ${ }^{76}$. Similarly, patients with peritoneal carcinomatosis should be considered as a complex oncological group at high risk of infectious complication - the most important cause of peri-operative morbidity and death in CRS/HI$\mathrm{PEC}^{77}$. Thus, we recommend ampicillin/sulbactan ${ }^{78}$ or cefoxitin over 24-72hs as antibiotic for infection prophylaxis, preferably as short-course regimens of $24 h^{78}$, while the use of antibiotic for therapeutic purpose should be guided by culture and sensitivities. On the other hand, the association of antimycotics should be indicated only when a fungal infection was presumed in the presence of neutropenia/fever or normal leukocytosis and neutropenia in patients with fever ${ }^{73,78,79}$. We also recommend vaccinations to reduce the risk of sepsis for patients in which splenectomy is presumable during CRS/HIPEC. These patients should receive pneumococcal and influenza immunization; patients not previously immunized should also receive Haemophilus influenza type $B$ and meningococcal group C conjugate vaccines ${ }^{80,81}$. As much as possible, especially because splenectomy increases major complication rate in patients undergoing CRS/HIPEC, we suggest this vaccine should be given at least two weeks before or 14 or more days after procedures ${ }^{82}$. 
Regarding the classification systems to be used for reporting complications related to $\mathrm{CRS} / \mathrm{HI}$ PEC, we follow the statement from the 5th International Consensus Metting on Peritoneal Surface Malignancies Treatment to adopt the joint $\mathrm{NCI} / \mathrm{NIH}$ Common Terminology Criteria for Adverse Events (CTCAE), last version ${ }^{83}$. However, because of different interpretations of severity grades of complications after CRS/HIPEC between this system and the therapy-oriented Clavien-Dindo classification ${ }^{84}$ - a universally-accepted classification in many surgical fields - we suggest that complications should be reported in both of these systems in order to permit comparison amongst different studies as well as with other comprehensive oncological and surgical procedures. As previously reported in the Milan consensus, the peritoneal cancer index (PCI) and the completeness of cytoreduction (CC) score described by Sugarbaker have been the recommended systems for intraoperative staging and classification for residual disease size, respectively since these experienced surgeons' naked-eye estimations were considered the ideal methods of assessment by the large majority of experts ${ }^{85,86}$.

\section{Intraperitoneal Chemotherapy Schedules (Ta- ble 1)}

Even though several regimens of drugs for HIPEC procedures are available, we suggest the following options for treatment of DMPM: (1) cisplatin $100 \mathrm{mg} / \mathrm{m}^{2}$ plus doxorubicin $15 \mathrm{mg} / \mathrm{m}^{2}$ or (2) carboplatin $800 \mathrm{mg} / \mathrm{m}^{2}$, both for $60 \mathrm{~min}$ at $4 \mathrm{~L}$ of perfusate ${ }^{56,87}$. For PMP and appendiceal tumors, the suggested protocols are (1) oxaliplatin $360 \mathrm{mg} / \mathrm{m} 2$ for $30 \mathrm{~min}$ or (2) cisplatin $100 \mathrm{mg} / \mathrm{m}^{2}$ plus doxorubicin $15 \mathrm{mg} / \mathrm{m}^{2}$ for $60 \mathrm{~min}$, both at $4 \mathrm{~L}$ of perfusate ${ }^{56}$. These drug dosages should be reduced by about $30 \%$ for patients over the age of 60-70 years, patients previously exposed to multiple lines of systemic chemotherapy, patients who needed GM-CSF rescue for febrile neutropenia while on systemic chemothe- rapy, patients who have received radiation therapy to bone-marrow bearing regions, and those who underwent extensive surgical cytoreduction due to high $\mathrm{PCl}$ scores $^{88,89}$. Accordingly, special attention is required for dose reduction of oxaliplatin to 200$250 \mathrm{mg} / \mathrm{m}^{2}$ in these cases because of the increased risk of postoperative hemorrhagic complications compared with HIPEC and other drugs90. For safety reasons, we point the dose limiting of $1000 \mathrm{mg} /$ $\mathrm{m}^{2}$ (or $200 \mathrm{mg} / \mathrm{m}^{2} / \mathrm{L}$ of perfusate) for carboplatin, total dose of $240 \mathrm{mg}$ (or $45 \mathrm{mg} / \mathrm{L}$ of perfusate) for cisplatin, $15 \mathrm{mg} / \mathrm{L}$ of perfusate for doxorubicin, and $460 \mathrm{mg} / \mathrm{m}^{2}$ for oxaliplatin ${ }^{56,87}$.

A major point concerning the proposed intraperitoneal chemotherapy schedules for CRS/ HIPEC procedures in Brazil is the current unavailability of mitomycin (MMC) in our country due to commercial matters. However, even though some data suggest that MMC might be a better agent for HIPEC delivery than oxaliplatin in patients suffering of peritoneal carcinomatosis of colorectal origins with favorable histologies and low burden of disease (i.e.: PSDSS I/II) ${ }^{91}$, contrary data also suggests that oxaliplatin offers a survival advantage over MMC in similar settings ${ }^{92}$, while a trend of better overall survival may also be noted in patients with unfavorable histologies and high burden of disease (i.e., PSDSS III/IV) treated with oxaliplatin ${ }^{91}$. In fact, the largest published data involving more than two thousand patients with PMP/appendiceal tumors treated by strategies of CRS/HIPEC in 16 specialized centers had demonstrated no significant benefit in terms of overall survival for HIPEC with Oxaliplatin vs. MMC (10y survival of $78 \%$ vs. $66 \%$, respectively; differences not statistically significant) ${ }^{4}$. But other wide data suggests that the use of oxaliplatin does not significantly increase the overall perioperative morbidity and/or mortality rates compared to a mitomycin- and doxorubicin-based protocols ${ }^{93}$. In these settings, we alternatively suggest the use of oxaliplatin for HIPEC delivery in PMP and apendicecal 
tumors especially because of the need for a lower perfusion time and the cisplatin plus doxorubicin protocol as an alternative lower-cost option. Similarly, due to the potential of increasing morbidity and complexity of procedures, we do not advoca- te the routine use of bidirectional oxaliplatin-based HIPEC regimens unless more convincing data could be available, or any intensification of the HIPEC protocol by adding irinotecan to the oxaliplatin-alone regimen ${ }^{94}$.

Table 1. Proposed chemotherapy schedules of HIPEC (closed abdomen technique) for treatment of Pseudomixoma peritonei (PMP) / Appendiceal Tumors and Diffuse Malignant Peritoneal Mesothelioma (DMPM).

\begin{tabular}{cl}
\hline Disease & \multicolumn{1}{c}{ Intraperitoneal Chemotherapy Schedules } \\
\hline PMP* & $\begin{array}{l}\text { Oxaliplatin } 360 \mathrm{mg} / \mathrm{m}^{2}, 30 \mathrm{~min} \text { at } 4 \mathrm{~L} \text { of perfusate; } \\
\text { or CDDP } 100 \mathrm{mg} / \mathrm{m}^{2} \text { plus doxorubicin } 15 \mathrm{mg} / \mathrm{m}^{2}, 60 \mathrm{~min} \text { at } 4 \mathrm{~L} \text { of perfusate. }\end{array}$ \\
DMPM & $\begin{array}{l}\text { CDDP } 100 \mathrm{mg} / \mathrm{m}^{2} \text { plus doxorubicin } 15 \mathrm{mg} / \mathrm{m}^{2}, 60 \mathrm{~min} \text { at } 4 \mathrm{~L} \text { of perfusate; } \\
\text { or Carboplatin } 800 \mathrm{mg} / \mathrm{m}, 60 \mathrm{~min} \text { at } 4 \mathrm{~L} \text { of perfusate. }\end{array}$
\end{tabular}

* Pseudomixoma peritonei (PMP) and appendiceal epithelial neoplasms.

\section{Perioperative Oncological Management}

Perioperative oncological management involving systemic therapies for both of these conditions is not clearly supported by randomized controlled trials, but a review of data from experienced centers has provided some evidence to this issue. For DMPM, neoadjuvant chemotherapy was not associated with increased completeness of cytoreduction ${ }^{95}$ and may impact negatively the survival for patients who underwent CRS-HIPEC with curative intent, whereas adjuvant chemotherapy may delay recurrence and improve survival ${ }^{96}$. Thus, we suggest that upfront CRS plus platin-based HIPEC should be considered the standard approach for DMPM, while waiting for a stronger level of scientific evidence ${ }^{6,67,96}$. Systemic chemotherapy should be administered principally in patients with recurrent disease or at a high risk for recurrence, and in those who are not appropriate candidates for aggressive surgery or were not optimally debulked ${ }^{97}$. For PMP from appendiceal origin, prior chemotherapy treatment was also found as independent predictors for a poorer progression-free survival and overall survival according to the largest international registry study exploring the strategy of CRS/HIPEC ${ }^{4}$. However, subset analysis of this same data had confirmed the peritoneal mucinous carcinomatosis histopathologic subtype as an independent predictor of a poorer overall and disease-free survival ${ }^{4}$, in line with other reports that adenocarcinoma with signet ring cell and adenocarcinoid histomorphology contributes to the poor prognosis associated with peritoneal metastasis from appendiceal adenocarcinoma ${ }^{98}$. Herein, even though the possible benefit of neoadjuvant chemotherapy for high-grade tumors in general remains controversial ${ }^{99,100}$, preoperative systemic chemotherapy appears to improve the prognosis of patients with signet ring cell histology ${ }^{37}$, which suggests the need for some discussion in a multidisciplinary tumor board in order to decide about the best approach to each specific case. At this point, our recommendation is to consider the use of preoperative fluoropirimidine-based systemic chemotherapy for high-grade peritoneal metastasis from appendiceal adenocarcinoma with signet ring cell histology and moderate to high $\mathrm{PCI}$ scores $^{37,99}$. In the adjuvant settings, the use systemic therapies should be guided by stands for other advanced colorectal cancers, 
as appropriated.

Finally, regarding the use of early postoperative intraperitoneal chemotherapy (EPIC) in combination with CRS/HIPEC, our proposal of standardized procedures is not to routinely deliver EPIC for either PMP/appendiceal tumors or DMPM, since this additional procedure is associated with an increased rate of complications and no clear benefit in terms of survival7,13,14, whereas HIPEC-alone protocols are much simpler for patient, surgeon, and nursing care ${ }^{13}$. As previously reported, the use of EPIC did not translate to better survival outcomes in the largest surgical series exploring CRS/HIPEC for the treatment of PMP/appendiceal tumors ${ }^{4}$ or DMPM ${ }^{6}$, which support the proposal being presented. Thus, this BSSO committee suggests the use of EPIC as an alternative treatment option for treatment of these both malignancies only when HIPEC is not available.

\section{CONCLUSION}

Practices of CRS/HIPEC are widely variable and standardization of such practices may enhance patient outcomes and improve care standards across all centers that offer this procedure in Brazil. Herein, we have reviewed the main worldwide variations for the treatment of PMP/appendiceal tumors and DMPM with CRS/HIPEC and thus proposed standards for common technical aspects, patient selection, intraperitoneal chemotherapy schedules and perioperative oncological managements. The effort of producing a nationally acceptable proposal to guide clinical practice concerning CRS/HIPEC procedures may contribute to producing homogeneous data that permits pooled analysis from the developing Brazilian register for peritoneal surface malignancies.

\section{ACKNOWLEDGMENTS}

The BSSO committee on peritoneal surface malignancies and HIPEC would like to thank Paul $\mathrm{H}$. Sugarbaker, M.D., Ph.D., from the Peritoneal Surface Oncology Program, MedStar Washington Hospital Center, Washington DC, USA; Vic J. Verwaal, M.D., Ph.D., from Department of Surgery, Aarhus University Hospital, Aarhus, Denmark; and Marcello Deraco, M.D., Ph.D., from Peritoneal Surface Malignancy Program, National Cancer Institute, Milan, Italy, for the external reviews of this paper as described in methods.

\section{R E S U M O}

A cirurgia citorredutora com quimioterapia intraperitoneal hipertérmica emergiu como um importante tratamento das neoplasias peritoneais e é, atualmente, o padrão de atendimento para neoplasias epiteliais do apêndice associadas à síndrome de pseudomixoma peritoneal, bem como para o mesotelioma peritoneal maligno difuso. No mundo, existem algumas variações reconhecidas das técnicas de cirurgia citorredutora e quimioterapia intraperitoneal hipertérmica, entretanto nenhuma técnica até agora demonstrou sua superioridade sobre o outra. Portanto, a padronização destes procedimentos poderia melhorar a prática clínica e permitir a comparação adequada entre os resultados. Neste cenário, a Sociedade Brasileira de Cirurgia Oncológica considera importante a apresentação de uma proposta de padronização de procedimentos de cirurgia citorredutora com quimioterapia intraperitoneal hipertérmica no Brasil, com um foco especial na produção de dados homogêneos para o desenvolvimento do registro brasileiro das neoplasias peritoneais.

Descritores: Injeções Intraperitoneais. Hipertermia Induzida. Quimioterapia. Neoplasias Peritoneais.

\section{REFERÊNCIAS}

1. Lambert LA. Looking up: recent advances in understanding and treating peritoneal carcinomatosis. CA Cancer J Clin. 2015;65(4):28498.

2. Passot G, Vaudoyer D, Villeneuve L, Kepenekian
V, Beaujard AC, Bakrin N, et al. What made hyperthermic intraperitoneal chemotherapy an effective curative treatment for peritoneal surface malignancy: a 25-year experience with 1,125 procedures. J Surg Oncol. 2016;113(7):796-803.

3. Levine EA, Stewart JH 4th, Shen P, Russell GB, Loggie $\mathrm{BL}$, Votanopoulos KI. Intraperitoneal chemotherapy 
for peritoneal surface malignancy: experience with 1,000 patients. J Am Coll Surg. 2014;218(4):57385

4. Chua TC, Moran BJ, Sugarbaker PH, Levine EA, Glehen O, Gilly FN, et al. Early- and long-term outcome data of patients with pseudomyxoma peritonei from appendiceal origin treated by a strategy of cytoreductive surgery and hyperthermic intraperitoneal chemotherapy. J Clin Oncol. 2012;30(20):2449-56.

5. $\mathrm{PH}$, Sugarbaker. Newstandard of care for appendiceal epithelial neoplasms and pseudomyxoma peritonei syndrome? Lancet Oncol 2006;7(1):69-76.

6. Yan TD, Deraco M, Baratti D, Kusamura S, Elias $D$, Glehen $\mathrm{O}$, et al. Cytoreductive surgery and hyperthermic intraperitoneal chemotherapy for malignant peritoneal mesothelioma: multi-institutional experience. J Clin Oncol. 2009;27(36):6237-42.

7. Helm JH, Miura JT, Glenn JA, Marcus RK, Larrieux $G$, Jayakrishnan TT, et al. Cytoreductive surgery and hyperthermic intraperitoneal chemotherapy for malignant peritoneal mesothelioma: a systematic review and meta-analysis. Ann surg Oncol. 2015;22(5):1686-93.

8. Witkamp AJ, de Bree E, Van Goethem R, Zoetmulder FA. Rationale and techniques of intra-operative hyperthermic intraperitoneal chemotherapy. Cancer Treat Rev. 2001;27(6):365-74.

9. Sugarbaker PH. Laboratory and clinical basis for hyperthermia as a component of intracavitary chemotherapy. Int J Hyperthermia. 2007;23(5):43142.

10. Hettinga JV, Konings AW, Kampinga HH. Reduction of cellular cisplatin resistance by hyperthermia - a review. Int J Hyperthermia. 1997;13(5):439-57.

11. Zunino B, Rubio-Patiño C, Villa E, Meynet O, Proics $E$, Cornille $A$, et al. Hyperthermic intraperitoneal chemotherapy leads to an anticancer immune response via exposure of cell surface heat shock protein 90. Oncogene. 2016;35(2):261-8.

12. Pelz JO, Vetterlein M, Grimmig T, Kerscher AG, Moll E, Lazariotou M, et al. Hyperthermic intraperitoneal chemotherapy in patients with peritoneal carcinomatosis: role of heat shock proteins and dissecting effects of hyperthermia. Ann Surg Oncol. 2013;20(4):1105-13.

13. McConnell YJ, Mack LA, Francis WP, Ho T, Temple WJ. HIPEC + EPIC versus HIPEC-alone: differences in major complications following cytoreduction surgery for peritoneal malignancy. J Surg Oncol. 2013;107(6):591-6.

14. Lam JY, McConnell YJ, Rivard JD, Temple WJ, Mack LA. Hyperthermic intraperitoneal chemotherapy + early postoperative intraperitoneal chemotherapy versus hyperthermic intraperitoneal chemotherapy alone: assessment of survival outcomes for colorectal and high-grade appendiceal peritoneal carcinomatosis. Am J Surg. 2015;210(3):424-30.

15. Baiocchi G, Ferreira FO, Mantoan H, da Costa AA, Faloppa CC, Kumagai LY, et al. Hyperthermic intraperitoneal chemotherapy after secondary cytoreduction in epithelial ovarian cancer: a singlecenter comparative analysis. Ann Surg Oncol. 2016;23(4):1294-301.

16. Akaishi E, Teixeira F, Katayama M, Mizumoto N, Costa FP, Buzaid AC, et al. Peritonectomy for peritoneal carcinomatosis: long-term outcomes from a single Brazilian institution. World J Surg. 2009;33(4):835-9; discussion 840.

17. Costa WL Jr, Coimbra FJ, Ribeiro HS, Diniz AL, de Godoy AL, Begnami M, et al. Safety and preliminary results of perioperative chemotherapy and hyperthermic intraperitoneal chemotherapy (HIPEC) for high-risk gastric cancer patients. World J Surg Oncol. 2012;10:195.

18. Albuquerque TLC, Von Sohsten AKA, Rodas AKF, Weinstein L, Reis TJCC. Anesthesia in patients undergoing cytoreductive surgery (CS) and intraoperative hyperthermic chemotherapy (HIPEC) [abstract]. Eur J Surg Oncol. 2015;41(Suppl 1):S199.

19. Velasquez ARE, Quadros CA, Vieira LV, Prisco E, Cangussú HC, Silva RGM, et al. Morbidity and mortality of patients undergoing cytoreductive surgery and intraperitoneal chemotherapy (HIPEC) at São Rafael Hospital between 2011 and 2015 [abstract]. Eur J Surg Oncol. 2015;41(Suppl 1):S201-S202

20. Vieira HC, Viana RFR, Lopes PVA, Moreira RCL, Rausch M, Salles PGO. Malignant peritoneal 
mesothelioma: a case report [abstract]. Eur J Surg Oncol. 2015;41(Suppl 1):S199.

21. Firmino NLJ, Soares MC, Miranda E, Azevedo LW, Gomes GES, Diniz AF, et al. A succesful case of HIPEC in a peritoneal mesothelioma patient [abstract]. Eur J Surg Oncol. 2015;41(Suppl 1):S199-200.

22. Oliveira DNA, Batista TP, Carneiro VCG, Tancredi R, Badiglian-Filho L, Leão CS. Cytoreductive surgery (CRS) plus hyperthermic intraperitoneal chemotherapy (HIPEC) for treatment of advanced ovarian cancer: the first two cases of a pioneering clinical trial in Brazil [abstract]. Eur J Surg Oncol 2015 Oct 15;41(Suppl 1):S200.

23. Reis TJCC, Ramalho WC, Barreto CL, Rodas AKF, Albuquerque $T C L$, Weinstein $L$, et al. Cytoreductive surgery and HIPEC: experience of the first patients operated in a public hospital [abstract]. Eur J Surg Oncol. 2015;41(Suppl 1):S200.

24. Cordeiro EZ, Baretta R, Silva CS, Bordinhao RW. Cytoreductive surgery and HIPEC for peritoneal metastasis by colon and appendix carcinoma [abstract]. Eur J Surg Oncol. 2015;41(Suppl 1):S200201.

25. Reis TJCC, Ramalho WC, Rodas AKF, Albuquerque $T C L$, Weinstein L, Gomes GES, et al. Economical feasibility of cytoreductive surgery and HIPEC by SUS [abstract]. Eur J Surg Oncol. 2015;41(Suppl 1):S201.

26. Brito FPB, Vieira SC, Morais Júnior MA, Silva MCA, Lopes AS, Ribeiro MMM. Intraperitoneal hyperthermic chemotherapy with high $\mathrm{PCl}$ and disease-free survival after 5 years: a case report [abstract]. Eur J Surg Oncol. 2015;41(Suppl 1):S201.

27. Cereser Junior $\mathrm{CH}$, Giordani DSN, Weston AC, Pessini SA, Sugarbaker PH, Meinhardt Junior JG. Ovarian cancer with carcinomatosis: a case report [abstract]. Eur J Surg Oncol. 2015;41(Suppl 1):S202.

28. Reis TJCC, Ramalho WC, Miranda ACG, Pereira CGS, Weinstein L, Lima MBA, et al. Positive impact of nutritional, anti-inflammatory and antihistamine therapy preoperatively in patients undergoing cytoreductive surgery and HIPEC [abstract]. Eur J Surg Oncol. 2015;41(Suppl 1):S202.

29. Takahashi RM, Aguiar-Junior S, Lopes A, Nakagawa WT, Calsavara VF, Ferreira FO. White-blood-cell count, lactate and C-reactive protein postoperative measures are associated with major complications following cytoreductive surgery and hyperthermic intraperitoneal chemotherapy [abstract]. Eur J Surg Oncol. 2015;41(Suppl 1):S203.

30. Maciver AH, Al-Sukhni E, Esquivel J, Skitzki JJ, Kane JM 3rd, Francescutti VA. Current delivery of Hyperthermic Intraperitoneal Chemotherapy with Cytoreductive Surgery (CS/HIPEC) and perioperative practices: an international survey of high-volume surgeons. Ann Surg Oncol. 2017;24(4):923-30.

31. Cotte E, Passot G, Gilly FN, Glehen O. Selection of patients and staging of peritoneal surface malignancies. World J Gastrointest Oncol. 2010;2(1):31-5.

32. Yan TD, Morris DL, Shigeki K, Dario B, Marcello D. Preoperative investigations in the management of peritoneal surface malignancy with cytoreductive surgery and perioperative intraperitoneal chemotherapy: expert consensus statement. J Surg Oncol. 2008;98(4):224-7.

33. Taflampas P, Dayal S, Chandrakumaran K, Mohamed F, Cecil TD, Moran BJ. Pre-operative tumour marker status predicts recurrence and survival after complete cytoreduction and hyperthermic intraperitoneal chemotherapy for appendiceal Pseudomyxoma Peritonei: analysis of 519 patients. Eur J Surg Oncol. 2014;40(5):515-20.

34. López-López V, Cascales-Campos PA, Schneider MA, Gil J, Gil E, Gomez-Hidalgo NR, et al. Cytoreductive surgery and hyperthermic intraperitoneal chemotherapy (HIPEC) in elderly patients. A systematic literature review. Surg Oncol. 2016;25(4):378-384.

35. Alyami $M$, Lundberg $P$, Kepenekian $V$, Goéré $D$, Bereder JM, Msika S, Lorimier G, Quenet F, Ferron G, Thibaudeau E, Abboud K, Lo Dico R, Delroeux D, Brigand C, Arvieux C, Marchal F, Tuech JJ, Guilloit JM, Guyon F, Peyrat P, Pezet D, Ortega-Deballon P, Zinzindohoue $F$, de Chaisemartin $C$, Kianmanesh R, Glehen O, Passot G; BIG-RENAPE and RENAPE Working Groups. Cytoreductive surgery and hyperthermic intraperitoneal chemotherapy for peritoneal carcinomatosis in the elderly: a casecontrolled, multicenter study. Ann Surg Oncol. 
2016;23(Suppl 5):737-45.

36. Carr NJ, Cecil TD, Mohamed F, Sobin LH, Sugarbaker PH, González-Moreno S, Taflampas P, Chapman S, Moran BJ; Peritoneal Surface Oncology Group International. A consensus for classification and pathologic reporting of Pseudomyxoma Peritonei and associated appendiceal neoplasia: the results of the Peritoneal Surface Oncology Group International (PSOGI) Modified Delphi Process. Am J Surg Pathol. 2016;40(1):14-26.

37. Milovanov V, Sardi A, Studeman K, Nieroda C, Sittig M, Gushchin V. The 7th Edition of the AJCC Staging Classification Correlates with Biologic Behavior of Mucinous Appendiceal Tumor with Peritoneal Metastases Treated with Cytoreductive Surgery and Hyperthermic Intraperitoneal Chemotherapy (CRS/ HIPEC). Ann Surg Oncol. 2016;23(6):1928-33.

38. Husain AN, Colby T, Ordonez N, Krausz T, Attanoos $R$, Beasley MB, Borczuk AC, Butnor K, Cagle PT, Chirieac LR, Churg A, Dacic S, Fraire A, GalateauSalle F, Gibbs A, Gown A, Hammar S, Litzky L, Marchevsky AM, Nicholson AG, Roggli V, Travis WD, Wick $M$; International Mesothelioma Interest Group. Guidelines for pathologic diagnosis of malignant mesothelioma: 2012 update of the consensus statement from the International Mesothelioma Interest Group. Arch Pathol Lab Med. 2013;137(5):647-67.

39. Hjerpe A, Ascoli V, Bedrossian C, Boon M, Creaney J, Davidson B, et al. Guidelines for cytopathologic diagnosis of epithelioid and mixed type malignant mesothelioma. Complementary statement from the International Mesothelioma Interest Group, also endorsed by the International Academy of Cytology and the Papanicolaou Society of Cytopathology. Cytojournal. 2015;12:26.

40. Yan TD, Deraco M, Elias D, Glehen O, Levine EA, Moran BJ, Morris DL, Chua TC, Piso P, Sugarbaker $\mathrm{PH}$; Peritoneal Surface Oncology Group. A novel tumor-node-metastasis (TNM) staging system of diffuse malignant peritoneal mesothelioma using outcome analysis of a multi-institutional database. Cancer. 2011;117(9):1855-63.

41. Pillai K, Pourgholami MH, Chua TC, Morris DL. Prognostic significance of Ki67 expression in malignant peritoneal mesothelioma. Am J Clin Oncol. 2015;38(4):388-94.

42. Kusamura S, Torres Mesa PA, Cabras A, Baratti D, Deraco M. The Role of Ki-67 and pre-cytoreduction parameters in selecting Diffuse Malignant Peritoneal Mesothelioma (DMPM) patients for Cytoreductive Surgery (CRS) and Hyperthermic Intraperitoneal Chemotherapy (HIPEC). Ann Surg Oncol. 2016;23(5):1468-73.

43. Baratti D, Kusamura S, Cabras AD, Bertulli R, Hutanu I, Deraco M. Diffuse malignant peritoneal mesothelioma: long-term survival with complete cytoreductive surgery followed by hyperthermic intraperitoneal chemotherapy (HIPEC). Eur J Cancer. 2013;49(15):3140-8.

44. Verwaal VJ, Kusamura S, Baratti D, Deraco M. The eligibility for local-regional treatment of peritoneal surface malignancy. J Surg Oncol. 2008;98(4):2203.

45. Esquivel J, Elias D, Baratti D, Kusamura S, Deraco M. Consensus statement on the loco regional treatment of colorectal cancer with peritoneal dissemination. J Surg Oncol. 2008;98(4):263-7.

46. Sugarbaker PH. Peritonectomy procedures. Ann Surg. 1995;221(1):29-42.

47. Sugarbaker PH. Cytoreductive surgery using peritonectomy and visceral resections for peritoneal surface malignancy. Transl Gastrointest Cancer 2013;2(2):54-74.

48. Deraco M, Baratti D, Kusamura S, Laterza B, Balestra MR. Surgical technique of parietal and visceral peritonectomy for peritoneal surface malignancies. J Surg Oncol. 2009;100(4):321-8.

49. Spratt JS, Adcock RA, Muskovin M, Sherrill W, McKeown J. Clinical delivery system for intraperitoneal hyperthermic chemotherapy. Cancer Res. 1980;40(2):256-60.

50. Facy O, Combier C, Poussier M, Magnin G, Ladoire S, Ghiringhelli $F$, et al. High pressure does not counterbalance the advantages of open techniques over closed techniques during heated intraperitoneal chemotherapy with oxaliplatin. Surgery. 2015;157(1):72-8.

51. Halkia E, Tsochrinis A, Vassiliadou DT, Pavlakou A, Vaxevanidou A, Datsis A, et al. Peritoneal 
carcinomatosis: intraoperative parameters in open (coliseum) versus closed abdomen HIPEC. Int J Surg Oncol. 2015;2015:610597.

52. Rodríguez Silva C, Moreno Ruiz FJ, Bellido Estévez I, Carrasco Campos J, Titos García A, Ruiz López $M$, et al. Are there intra-operative hemodynamic differences between the Coliseum and closed HIPEC techniques in the treatment of peritoneal metastasis? A retrospective cohort study. World J Surg Oncol. 2017;15(1):51.

53. Raspé $C$, Flöther $L$, Schneider R, Bucher $M$, Piso $P$. Best practice for perioperative management of patients with cytoreductive surgery and HIPEC. Eur J Surg Oncol. 2017;43(6):1013-27. Epub 2016 Sep 28.

54. Rettenmaier MA, Mendivil AA, Gray CM, Chapman AP, Stone MK, Tinnerman EJ, et al. Intra-abdominal temperature distribution during consolidation hyperthermic intraperitoneal chemotherapy with carboplatin in the treatment of advanced stage ovarian carcinoma. Int J Hyperthermia. 2015;31(4):396-402.

55. Schaaf $L$, van der Kuip H, Zopf W, Winter S, Münch $M$, Mürdter $T E$, et al. A Temperature of $40^{\circ} \mathrm{C}$ Appears to be a Critical Threshold for Potentiating Cytotoxic Chemotherapy In Vitro and in Peritoneal Carcinomatosis Patients Undergoing HIPEC. Ann Surg Oncol. 2015;22 Suppl 3:S758-65.

56. Kusamura S, Dominique E, Baratti D, Younan R, Deraco M. Drugs, carrier solutions and temperature in hyperthermic intraperitoneal chemotherapy. J Surg Oncol. 2008 Sep 15;98(4):247-52.

57. Glehen O, Cotte E, Kusamura S, Deraco M, Baratti $D$, Passot $G$, et al. Hyperthermic intraperitoneal chemotherapy: nomenclature and modalities of perfusion. J Surg Oncol. 2008;98(4):242-6.

58. Batista TP, Badiglian-Filho L, Leão CS. Exploring flow rate selection in HIPEC procedures. Rev Col Bras Cir. 2016;43(6):476-79.

59. Mehta AM, Van den Hoven JM, Rosing $H$, Hillebrand MJ, Nuijen B, Huitema AD, et al. Stability of oxaliplatin in chloride-containing carrier solutions used in hyperthermic intraperitoneal chemotherapy. Int J Pharm. 2015;479(1):23-7.

60. Mehta AM, Huitema AD, Burger JW, Brandt-Kerkhof
AR, van den Heuvel SF, Verwaal VJ. Standard Clinical Protocol for Bidirectional Hyperthermic Intraperitoneal Chemotherapy (HIPEC): Systemic Leucovorin, 5-Fluorouracil, and Heated Intraperitoneal Oxaliplatin in a Chloride-Containing Carrier Solution. Ann Surg Oncol. 2017;24(4):990997. Epub 2016 Nov 28.

61. Caneparo A, Massucco P, Vaira M, Maina G, Giovale E, Coggiola $\mathrm{M}$, et al. Contamination risk for operators performing semi-closed HIPEC procedure using cisplatin. Eur J Surg Oncol. 2014;40(8):925-9.

62. Villa AF, El Balkhi S, Aboura R, Sageot H, HasniPichard $\mathrm{H}$, Pocard $\mathrm{M}$, et al. Evaluation of oxaliplatin exposure of healthcare workers during Heated Intraperitoneal Perioperative Chemotherapy (HIPEC). Ind Health. 2015;53(1):28-37.

63. Konate A, Poupon J, Villa A, Garnier R, Hasni-Pichard $H$, Mezzaroba D, et al. Evaluation of environmental contamination by platinum and exposure risks for healthcare workers during a Heated Intraperitoneal Perioperative Chemotherapy (HIPEC) procedure. J Surg Oncol. 2011;103(1):6-9.

64. Foster JM, Gupta PK, Carreau JH, Grotz TE, Blas JV, Gatalica Z, et al. Right hemicolectomy is not routinely indicated in pseudomyxoma peritonei. Am Surg. 2012;78(2):171-7.

65. Sugarbaker $\mathrm{PH}$. When and when not to perform a right colon resection with mucinous appendiceal neoplasms. Ann Surg Oncol. 2017;24(3):729-732. Epub 2016 Oct 21.

66. Kusamura S, O'Dwyer ST, Baratti D, Younan R, Deraco M. Technical aspects of cytoreductive surgery. J Surg Oncol. 2008;98(4):232-6.

67. Baratti D, Kusamura S, Cabras AD, Deraco M. Cytoreductive surgery with selective versus complete parietal peritonectomy followed by hyperthermic intraperitoneal chemotherapy in patients with diffuse malignant peritoneal mesothelioma: a controlled study. Ann Surg Oncol. 2012;19(5):141624.

68. Sugarbaker PH. Avoiding diverting ileostomy in patients requiring complete pelvic peritonectomy. Ann Surg Oncol. 2016;23(5):1481-5.

69. Riss S, Chandrakumaran K, Dayal S, Cecil TD, Mohamed F, Moran BJ. Risk of definitive stoma after 
surgery for peritoneal malignancy in 958 patients: comparative study between complete cytoreductive surgery and maximal tumor debulking. Eur J Surg Oncol. 2015;41(3):392-5.

70. de Cuba EM, Verwaal VJ, de Hingh IH, van Mens LJ, Nienhuijs SW, Aalbers AG, et al. Morbidity associated with colostomy reversal after cytoreductive surgery and HIPEC. Ann Surg Oncol. 2014;21(3):883-90.

71. Colantonio L, Claroni C, Fabrizi L, Marcelli ME, Sofra M, Giannarelli D, et al. A randomized trial of goal directed vs. standard fluid therapy in cytoreductive surgery with hyperthermic intraperitoneal chemotherapy. J Gastrointest Surg. 2015;19(4):722-9.

72. Mavroudis C, Alevizos L, Stamou KM, Vogiatzaki T, Eleftheriadis S, Korakianitis O, et al. Hemodynamic monitoring during heated intraoperative intraperitoneal chemotherapy using the FloTrac/ Vigileo system. Int Surg. 2015;100(6):1033-9.

73. Cascales Campos PA, Gil Martínez J, Galindo Fernández PJ, Gil Gómez E, Martínez Frutos IM, Parrilla Paricio P. Perioperative fast track program in intraoperative hyperthermic intraperitoneal chemotherapy (HIPEC) after cytoreductive surgery in advanced ovarian cancer. Eur J Surg Oncol. 2011;37(6):543-8.

74. Cascales-Campos PA, Sánchez-Fuentes PA, Gil J, Gil E, López-López V, Rodriguez Gomez-Hidalgo $\mathrm{N}$, et al. Effectiveness and failures of a fast track protocol after cytoreduction and hyperthermic intraoperative intraperitoneal chemotherapy in patients with peritoneal surface malignancies. Surg Oncol. 2016;25(4):349-354.

75. Glehen O, Osinsky D, Cotte E, Kwiatkowski F, Freyer $G$, Isaac S, et al. Intraperitoneal chemohyperthermia using a closed abdominal procedure and cytoreductive surgery for the treatment of peritoneal carcinomatosis: morbidity and mortality analysis of 216 consecutive procedures. Ann Surg Oncol. 2003;10(8):863-9.

76. López-Basave HN, Morales-Vasquez F, MendezHerrera C, Namendys-Silva SA, Luna-Ortiz K, Calderillo-Ruiz G, et al. Intensive care unit admission after cytoreductive surgery and hyperthermic intraperitoneal chemotherapy. Is it necessary? J
Oncol. 2014;2014:307317.

77. Arslan NC, Sokmen S, Avkan-Oguz V, Obuz F, Canda AE, Terzi $C$, et al. Infectious complications after cytoreductive surgery and hyperthermic intraperitoneal chemotherapy. Surg Infect (Larchmt). 2017;18(2):157-63.

78. Valle M, Federici O, Carboni F, Toma L, Gallo MT, Prignano $G$, et al. Postoperative infections after cytoreductive surgery and HIPEC for peritoneal carcinomatosis: proposal and results from a prospective protocol study of prevention, surveillance and treatment. Eur J Surg Oncol. 2014;40(8):950-6.

79. Gaspar GG, Menegueti MG, Auxiliadora-Martins M, Basile-Filho A, Martinez R. Evaluation of the predictive indices for candidemia in an adult intensive care unit. Rev Soc Bras Med Trop. 2015;48(1):77-82

80. Davies JM, Barnes R, Milligan D and Force; British Committee for Standards in Haematology. Working Party of the Haematology/Oncology Task. Update of guidelines for the prevention and treatment of infection in patients with an absent or dysfunctional spleen. Clin Med (Lond). 2002;2(5):440-3.

81. Moulis G, Lapeyre-Mestre $M$, Mahévas M, Montastruc JL, Sailler L. Need for an improved vaccination rate in primary immune thrombocytopenia patients exposed to rituximab or splenectomy. A nationwide population-based study in France. Am J Hematol. 2015;90(4):301-5.

82. Dagbert F, ThievenazR, Decullier E, Bakrin N, Cotte E, Rousset $\mathrm{P}$, et al. Splenectomy increases postoperative complications following cytoreductive surgery and hyperthermic intraperitoneal chemotherapy. Ann Surg Oncol. 2016;23(6):1980-5.

83. Younan R, Kusamura S, Baratti D, Cloutier AS, Deraco M. Morbidity, toxicity, and mortality classification systems in the local regional treatment of peritoneal surface malignancy. J Surg Oncol. 2008;98(4):253-7

84. Lehmann K, Eshmuminov D, Slankamenac K, Kranzbühler B, Clavien PA, Vonlanthen $R$, et al. Where Oncologic and Surgical Complication Scoring Systems Collide: Time for a New Consensus for CRS/HIPEC. World J Surg. 2016;40(5):1075-81. 
85. Portilla AG, Shigeki K, Dario B, Marcello D. The intraoperative staging systems in the management of peritoneal surface malignancy. J Surg Oncol. 2008;98(4):228-31.

86. González-Moreno S, Kusamura S, Baratti D, Deraco M. Postoperative residual disease evaluation in the locoregional treatment of peritoneal surface malignancy. J Surg Oncol. 2008;98(4):237-41.

87. Shetty SJ, Bathla L, Govindarajan V, Thomas P, Loggie BW. Comparison of cytoreductive surgery and hyperthermic intraperitoneal chemotherapy with mitomycin or carboplatin for diffuse malignant peritoneal mesothelioma. Am Surg. 2014;80(4):348-52.

88. Baratti D, Kusamura S, Laterza B, Balestra MR, Deraco M. Early and long-term postoperative management following cytoreductive surgery and hyperthermic intraperitoneal chemotherapy. World J Gastrointest Oncol. 2010;2(1):36-43.

89. González-Moreno S, González-Bayón LA, Ortega-Pérez G. Hyperthermic intraperitoneal chemotherapy: Rationale and technique. World J Gastrointest Oncol. 2010;2(2):68-75.

90. Charrier T, Passot G, Peron J, Maurice C, Gocevska $S$, Quénet $F$, et al. Cytoreductive surgery combined with hyperthermic intraperitoneal chemotherapy with oxaliplatin increases the risk of postoperative hemorrhagic complications: analysis of predictive factors. Ann Surg Oncol. 2016;23(7):2315-22.

91. Prada-Villaverde A, Esquivel J, Lowy AM, Markman M, Chua T, Pelz J, et al. The American Society of Peritoneal Surface Malignancies evaluation of HIPEC with Mitomycin C versus Oxaliplatin in 539 patients with colon cancer undergoing a complete cytoreductive surgery. J Surg Oncol. 2014;110(7):779-85.

92. Leung V, Huo YR, Liauw W, Morris DL. Oxaliplatin versus Mitomycin C for HIPEC in colorectal cancer peritoneal carcinomatosis. Eur J Surg Oncol. 2017;43(1):144-9.

93. Glockzin G, von Breitenbuch P, Schlitt HJ, Piso P. Treatment-related morbidity and toxicity of CRS and oxaliplatin-based HIPEC compared to a mitomycin and doxorubicin-based HIPEC protocol in patients with peritoneal carcinomatosis: a matched-pair analysisTreatment-related morbidity and toxicity of CRS and oxaliplatin-based HIPEC compared to a mitomycin and doxorubicinbased HIPEC protocol in patients with peritoneal carcinomatosis: a matched-pair analysis. J Surg Oncol. 2013;107(6):574-8.

94. Quenet F, Goéré D, Mehta SS, Roca L, Dumont F, Hessissen $M$, et al. Results of two bi-institutional prospective studies using intraperitoneal oxaliplatin with or without irinotecan during HIPEC after cytoreductive surgery for colorectal carcinomatosis. Ann Surg. 2011;254(2):294-301.

95. Deraco M, Baratti D, Hutanu I, Bertuli R, Kusamura $\mathrm{S}$. The role of perioperative systemic chemotherapy in diffuse malignant peritoneal mesothelioma patients treated with cytoreductive surgery and hyperthermic intraperitoneal chemotherapy. Ann Surg Oncol. 2013;20(4):1093-100.

96. Kepenekian V, Elias D, Passot G, Mery E, Goere D, Delroeux D, Quenet F, Ferron G, Pezet D, Guilloit JM, Meeus P, Pocard M, Bereder JM, Abboud K, Arvieux C, Brigand C, Marchal F, Classe JM, Lorimier G, De Chaisemartin C, Guyon F, Mariani P, Ortega-Deballon P, Isaac S, Maurice C, Gilly FN, Glehen O; French Network for Rare Peritoneal Malignancies (RENAPE). Diffuse malignant peritoneal mesothelioma: Evaluation of systemic chemotherapy with comprehensive treatment through the RENAPE Database: Multi-Institutional Retrospective Study. Eur J Cancer. 2016;65:69-79.

97. Kindler HL. Peritoneal mesothelioma: the site of origin matters. Am Soc Clin Oncol Educ Book. 2013:182-8.

98. hemelandu C, Sugarbaker PH. Clinicopathologic and prognostic features in patients with peritoneal metastasis from mucinous adenocarcinoma, adenocarcinoma with signet ring cells, and adenocarcinoid of the appendix treated with cytoreductive surgery and perioperative intraperitoneal chemotherapy. Ann Surg Oncol. 2016;23(5):1474-80.

99. Turner KM, Hanna NN, Zhu Y, Jain A, Kesmodel SB, Switzer RA, et al. Assessment of neoadjuvant chemotherapy on operative parameters and outcome in patients with peritoneal dissemination 
from high-grade appendiceal cancer. Ann Surg Oncol. 2013;20(4):1068-73.

100. Cummins KA, Russell GB, Votanopoulos KI, Shen $P$, Stewart JH, Levine EA. Peritoneal dissemination from high-grade appendiceal cancer treated with cytoreductive surgery (CRS) and hyperthermic intraperitoneal chemotherapy (HIPEC). J Gastrointest Oncol. 2016;7(1):3-9.
Recebido em: 26/05/2017

Aceito para publicação em: 08/06/2017

Conflito de interesse: nenhum.

Fonte de financiamento: nenhuma.

\section{Endereço para correspondência:}

Thales Paulo Batista

E-mail: t.paulo@outlook.com / t.paulo@bol.com.br 
In September/October 2017, the Journal of the Brazilian College of Surgeons (Rev Col Bras Cir. 2017;44(5):530-44)

published the original article titled "A proposal of Brazilian Society of Surgical Oncology for standardizing cytoreductive surgery plus hypertermic intraperitoneal chemotherapy procedures in Brazil: pseudomixoma peritonei, appendiceal tumors and malignant peritoneal mesothelioma." (http://dx.doi.org/10.1590/0100-69912017005016), by Thales Paulo Batista; Bruno José Queiroz Sarmento; Janina Ferreira Loureiro; Andrea Petruzziello; Ademar Lopes; Cassio Cortez Santos; Cláudio de Almeida Quadros; Eduardo Hiroshi Akaishi; Eduardo Zanella Cordeiro1; Felipe José Fernández Coimbra; Gustavo Andreazza Laporte; Leonaldson Santos Castro; Ranyell Matheus Spencer Sobreira Batista; Samuel Aguiar Júnior; Wilson Luiz Costa Júnior; Fábio Oliveira Ferreira; Comitê de Neoplasias Peritoneais e Quimioterapia Intraperitoneal Hipertérmica da Sociedade Brasileira de Cirurgia Oncológica. The following errors were identified:

Title:

Reads: "A proposal of Brazilian Society of Surgical Oncology for standardizing cytoreductive surgery plus hypertermic intraperitoneal chemotherapy procedures in Brazil: pseudomixoma peritonei, appendiceal tumors and malignant peritoneal mesothelioma";

Should read: "A proposal of Brazilian Society of Surgical Oncology (BSSO/SBCO) for standardizing cytoreductive surgery (CRS) plus hyperthermic intraperitoneal chemotherapy (HIPEC) procedures in Brazil: pseudomixoma peritonei, appendiceal tumors and malignant peritoneal mesothelioma.".

\section{Authors:}

Reads: "Thales Paulo Batista; Bruno José Queiroz Sarmento; Janina Ferreira Loureiro; Andrea Petruzziello; Ademar Lopes; Cassio Cortez Santos; Cláudio de Almeida Quadros; Eduardo Hiroshi Akaishi; Eduardo Zanella Cordeiro'; Felipe José Fernández Coimbra; Gustavo Andreazza Laporte; Leonaldson Santos Castro; Ranyell Matheus Spencer Sobreira Batista; Samuel Aguiar Júnior; Wilson Luiz Costa Júnior; Fábio Oliveira Ferreira; Comitê de Neoplasias Peritoneais e Quimioterapia Intraperitoneal Hipertérmica da Sociedade Brasileira de Cirurgia Oncológica"

Should read: "Thales Paulo Batista; Bruno José Queiroz Sarmento; Janina Ferreira Loureiro; Andrea Petruzziello; Ademar Lopes; Cassio Cortez Santos; Cláudio de Almeida Quadros; Eduardo Hiroshi Akaishi; Eduardo Zanella Cordeiro'; Felipe José Fernández Coimbra; Gustavo Andreazza Laporte; Leonaldson Santos Castro; Ranyell Matheus Spencer Sobreira Batista; Samuel Aguiar Júnior; Wilson Luiz Costa Júnior; Fábio Oliveira Ferreira; on behalf of the BSSO/ SBCO Committee on Peritoneal Surface Malignancies and HIPEC"

\footnotetext{
Abstract:

Reads: "hypertermic"

Should read: "hyperthermic"
} 